\title{
Risk Assessment for Preterm Delivery using the Fetal Fibronectin Test Associated with the Measurement of Uterine Cervix Length in Symptomatic Pregnant Women
}

\section{Avaliação do risco para parto pré-termo utilizando o teste da fibronectina fetal, associado à medida de comprimento de colo uterino, em gestantes sintomáticas}

\author{
Tadeu Rodriguez de Carvalho Pinheiro Filho ${ }^{1}$ Vanessa Rocha Pessoa ${ }^{2}$ Thaisa de Sousa Lima ${ }^{2}$ \\ Marcela Melo de Castro $^{2}$ José Juvenal Linhares ${ }^{1,2}$ \\ ${ }^{1}$ Gynecology and Obstetrics Residency Program, Santa Casa de \\ Misericórdia de Sobral, Sobral, CE, Brazil \\ 2 Faculty of Medicine, Universidade Federal do Ceará, Sobral, CE, Brazil \\ Address for correspondence Tadeu Rodriguez de Carvalho Pinheiro \\ Filho, MD, Santa Casa de Misericórdia de Sobral, Avenida Dr. Guarani, \\ 115, 62042-030, Derby Clube, Sobral, CE, Brazil \\ (e-mail: tadeurcpfilho@gmail.com).
}

Rev Bras Ginecol Obstet 2018;40:507-512.

\begin{abstract}
Keywords

- cervical length measurement

- fibronectin

- pregnancy

- preterm labor

- risk

Objective To analyze the use of the measurement of uterine cervix length (MUCL) and the fetal fibronectin (fFN) rapid test as predictors of preterm delivery (PTD) in symptomatic pregnant women assisted at the Santa Casa de Misericórdia de Sobral Maternity Hospital.

Methods This was a prospective and analytic study involving 53 parturients assisted between September of 2015 and July of 2016; the participants were between 24 and 34 weeks of gestational age (GA) and presented complaints related to preterm labor (PTL) prodromes. Vaginal secretion was collected for fFN testing, and the MUCL was obtained via transvaginal ultrasonography.

Results A total of $58.49 \%$ of the subjects showed $\mathrm{MUCL}<25 \mathrm{~mm}$, and $41.51 \%$ were positive in the fFN rapid test. A total of 48 patients were followed-up until their delivery date, and $54.17 \%$ resulted in PTL. The relative risk (RR) for PTD in patients with MUCL $<25 \mathrm{~mm}$ was 1.83 ( $p=0.09,0.99-3.36,95 \%$ confidence interval [Cl]), with a mean time before delivery of 2.98 weeks. Based on fFN positive results, the RR was $3.50(p=0.002,1.39-$ $8.79,95 \% \mathrm{Cl})$ and the mean time until delivery was 1.94 weeks. The RR was $2.70(p=0.002$, $1.08-6.72,95 \% \mathrm{Cl})$ when both tests were used. The RR of PTD within 48 hours, and 7 and 14 days were, respectively, $1.30(p=0.11,95 \% \mathrm{Cl} 1.02-1.67), 1.43(p=0.12,95 \% \mathrm{Cl} \%$ 0.99-2.06), and 2.03 ( $p=0.008,95 \% \mathrm{Cl} 1.26-3.27)$, when based on the MUCL, and 1.75 $(p=0.0006,95 \% \mathrm{Cl} 1.20-2.53), 2.88(p=0.0001,95 \% \mathrm{Cl}, 1.57-5.31)$, and 3.57 ( $p=0.0002,95 \% \mathrm{Cl} 1.63-7.81)$ when based on positive fFN results. The RR at 48 hours and 7 and 14 days considering both tests was 1.74 ( $p=0.0001,95 \% \mathrm{Cl} 1.14-2.64), 2.22$ $(p=0.0001,95 \% \mathrm{Cl} 1.22-4.04)$, and $2.76(p=0.0002,95 \% \mathrm{Cl} 1.27-5.96)$, respectively.
\end{abstract}

received

May 14, 2017

accepted

May 21, 2018
DOI https://doi.org/

10.1055/s-0038-1667185. ISSN 0100-7203.
Copyright $(2018$ by Thieme Revinter

Publicações Ltda, Rio de Janeiro, Brazil
License terms

(c) (1) 


\section{Resumo}

Palavras-chave
- medida do
comprimento cervical
- fibronectina
- gravidez
- trabalho de parto
prematuro
- risco

Conclusion In symptomatic pregnant women, we concluded that the $\mathrm{MUCL}<25$ $\mathrm{mm}$ associated with positive fFN rapid test indicate increased the risk for PTD. Further studies with larger sample sizes could contribute in supporting the results presented in the current study.

Objetivo Analisar a utilização da medida do comprimento do colo uterino (MCCU), e do teste da fibronectina fetal (FNf) como preditores do trabalho de parto pré-termo (PPT), em gestantes sintomáticas, atendidas na Maternidade da Santa Casa de Misericórdia de Sobral.

Métodos Foi realizado um estudo prospectivo e analítico, envolvendo 53 parturientes atendidas no período de setembro de 2015 a julho de 2016, com idade gestacional (IG) entre 24 e 34 semanas que tiveram queixas relacionadas a pródromos de trabalho de parto prematuro (TPP), sendo realizada coleta de secreção vaginal para FNf e MCCU por via ultrassonográfica transvaginal.

Resultados Um total de 58,49\% das pacientes tinham MCCU $<25$ mm, e 41,51\% tiveram teste rápido de fFN positivo. Foi feito o acompanhamento de 48 pacientes, com $54,17 \%$ de PPTs. O risco relativo (RR) para PPT com MCCU $<25 \mathrm{~mm}$ foi de 1,83 ( $p=0,09,0,99-3,36$, intervalo de confiança [IC] 95\%), com média de tempo até o parto de 2,98 semanas. Para fFN, o RR foi de 3.50 ( $p=0.002,1.39-8.79$, IC $95 \%$ ) e a média até o parto foi de 1,94 semanas. Quando os dois testes foram positivos, o RR foi de $2,70(1,08-6,72)$. Para a MCCU, o RR para PPT em 48 horas, 7 e 14 dias foram 1,30 ( $p=0.11,95 \%$ IC 1.02-1.67), 1,43 ( $p=0.12,95 \% \mathrm{Cl} \% 0.99-2.06)$ e 2,03 ( $p=0.008$, 95\% IC 1.26-3.27), respectivamente. Para FNf, em 48 horas, 7 e 14 dias foi de 1,75 $(p=0.0006,95 \%$ IC $1.20-2.53,2,88(p=0.0001,95 \%$ IC, $1.57-5.31)$ e 3,57 ( $p=0.0002,95 \%$ IC 1.63-7.81) respectivamente. Com os dois testes, o RR em 48 horas, 7 e 14 dias foi 1,74 ( $p=0.0001,95 \% \mathrm{IC} 1.14-2.64), 2,22$ ( $p=0.0001,95 \% \mathrm{IC}$ $1.22-4.04)$ e 2,76 ( $p=0.0002,95 \%$ IC $1.27-5.96)$ respectivamente.

Conclusão Em mulheres grávidas sintomáticas, concluímos que a MCCU $<25 \mathrm{~mm}$ e o teste rápido de FNf positivo indicam aumento do risco de PPT. Outros estudos com tamanhos de amostra maiores podem contribuir para apoiar os resultados apresentados no presente estudo.

\section{Introduction}

Preterm delivery (PTD), defined as occurring before 37 weeks of gestational age (GA), has an incidence of 11 to $18 \%$ of all pregnancies and is the main determinant of neonatal morbidity and mortality. ${ }^{1}$ This rate has remained constant in the past 50 years despite the various advances in medicine, therefore indicating that primary and secondary prevention interventions are occurring inadequately. ${ }^{2,3}$ This rate remains at an average of $9.9 \%$ in Brazil. ${ }^{4}$

Preterm delivery is responsible for $75 \%$ of the cases of prematurity; the remaining $25 \%$ resulting from elective situations, such as preeclampsia, diabetes, fetal distress, and others. The etiology of PTD includes numerous risk factors; however, its mechanism remains uncertain. ${ }^{5}$ Risk factors for PTD include a history of previous PTD, twinning, bleeding during the second half of gestation, infections (chorioamnionitis, pyelonephritis, and asymptomatic bacteriuria), black ethnicity, maternal age under 16 years or above
35 years, smoking, chronic or acute maternal diseases, anemia, uterine malformations, trauma, placenta previa, placental abruption, intrauterine growth retardation, and drug use. Nevertheless, these risk factors occur in only $50 \%$ of all PTD cases, and they eventually contribute to the identification of risk pregnancies. ${ }^{4-7}$ The most important risk factor is a history of prior PTD. 8,9

Recent studies demonstrate that the incidence of prematurity can be attenuated through the use of the MUCL, evaluated at the end of the second trimester by transvaginal ultrasonography (TVUS), to predict the probability of spontaneous PTD. ${ }^{10,11}$

Another useful test is the evaluation of the presence of fetal fibronectin (fFN) in vaginal secretion. Fetal fibronectin is an adhesive glycoprotein produced by the trophoblast, present in the maternal-fetal interface, which becomes detectable in the first half of the pregnancy and after 35 weeks of GA. This protein will only be present in situations of mechanical or inflammatory alterations due to damage to membranes or placenta between 
22 and 35 weeks of GA. The detection of fFN in pregnant women with GA between 22 and 37 weeks can indicate the probability of evolution to spontaneous PTD; this measurement has a high negative predictive value, therefore preventing unnecessary hospitalizations and interventions. ${ }^{4,6}$

Current studies show that the use of the MUCL in combination with the detection of fFN increases the sensitivity in predicting PTD. Iams et $\mathrm{al}^{2}$ report very high rates of PTD recurrence $(64 \%)$ in women with a positive fFN test result and short MUCL (under $25 \mathrm{~mm}$ ) in a multicenter study with 1,282 asymptomatic pregnant women with a previous history of PTD. In that study, fFN appeared as the most powerful predictor factor for PTD; in women with MUCL above $35 \mathrm{~mm}$, the PTD recurrence rate was $7 \%$ when fFN was negative compared with $28 \%$ in those with positive fFN test result. These authors emphasize that the importance of these tests is greatest in pregnant women presenting risk factors for PTD. In the case of pregnant women with no history of previous PTD, the risk of birth before 35 weeks of GA was reported as $13 \%$ when the fFN test was positive and $8 \%$ when MUCL was shorter than $25 \mathrm{~mm}$. Conversely, when there was a history of previous PTD, the probability of a new event was $40 \%$ for those with positive fFN and $30 \%$ for those with short MUCL. ${ }^{12}$

Hence, this study evaluated the risk of PTD through MUCL and fFN rapid-test results in pregnant women hospitalized at Hospital Maternidade Santa Casa de Misericórdia de Sobral (SCMS, in the Portuguese acronym), with complaints related to preterm labor (PTL) prodromes.

\section{Methods}

This was an analytical, prospective, invasive, and non-interventional study, performed at the SCMS with pregnant women presenting suggestive PTL symptoms, who were hospitalized between September of 2015 and July of 2016. The sample size was calculated for convenience and nonprobability sampling.

The study was approved by the respective Ethics Committee in Research under protocol number CAAE: 03996612.3.0000. 5053.

The inclusion criteria were: pregnant women with PTLrelated complaints, at GAs between 24 and 34 weeks, with cervix dilation $\leq 2 \mathrm{~cm}$, and voluntarily acceptance to participate in the study upon signing the free and informed consent term (all lengths of uterine cervix were included).

The exclusion criteria were: patients with transvaginal bleeding, broken amniotic sac, twin gestation, with reduced cognition/consciousness, and those who underwent vaginal touch, used vaginal medications or douche, and had sexual intercourse in the 24 hours prior to study selection.

Initially, the endocervical material was collected from participants using only a sterile swab; these samples were used to detect fibronectin through the fFN rapid test. The presence of fibronectin in the cervical sample was determined qualitatively. The vaginal touch would only be performed after the collection of endocervical material. Subsequently, the MUCL was performed by TVUS. The following criteria were adopted to ensure uniformity in this measurement: the internal cervical orifice should be clearly visible with a gentle depression as an isosceles or funnel triangle; the entire length of the cervical canal should be clearly visible; the external cervical orifice should be visible symmetrically; the external cervix surface should be clearly identified; the endocervical funnel, if present, was not included in the MUCL.

All cervix measurements were performed by the same examiner as well as the sample collections for the fFN test. The cervix was determined as short when the length was under $25 \mathrm{~mm}$. Other data were collected through an interview based on a form with predefined questions addressing socioeconomic, reproductive, and clinical-obstetric information. The follow-up until delivery of outcomes on data annotation was conducted through telephone contact with these pregnant women.

Data analysis was performed through the Epi-info software. The relative risk (RR) was calculated for each parameter with $95 \%$ confidence interval $(95 \% \mathrm{CI})$ and a significance level of $5 \%(p<0.05)$ in all tests. The risk assessment for PTD and testing for positive fFN, PTD and MUCL, and risk assessment when both variables were positive were all evaluated independently and included in the analysis. In addition, the risk for evolution to childbirth was evaluated at 48 hours, 7 days, and 14 days when the fFN and MUCL tests were each positive, separately or together.

\section{Results}

A total of 53 pregnant women were included in the analyses. The mean age was 22.80 years, $60.38 \%$ lived in urban areas, $52.83 \%$ had completed middle school education, and 62.26\% had a monthly income of up to 1 Brazilian minimum wage. The obstetric history showed that $56.60 \%$ of the patients were primiparous. Out of the non-primiparous patients, only $21.74 \%$ had a history of previous PTL. The mean GA at study admission was 31.83 weeks (-Table $\mathbf{1}$ ).

Almost all pregnant women received tocolysis when hospitalized $(88.68 \%)$, but when crossing that variable with preterm birth, we did not find a difference of risk $(\mathrm{RR}=1.39,95 \% \mathrm{CI}, 0.46-4.21, p=0.41)$.

The MUCL mean value measured by TVUS was $21.7 \mathrm{~mm}$ with a standard deviation of 0.89 and $75^{\text {th }}$ percentile at $28.0 \mathrm{~mm}$. The cut-off value of $25 \mathrm{~mm}$ used to transform this variable into a qualitative one showed that $58.49 \%$ of the participants had MUCL shorter than $25 \mathrm{~mm}$ at the time of study admission.

A total of $41.51 \%$ of participants showed positive fFN rapid-test results during study admission (-Table 1 ).

Out of the 53 patients initially analyzed, 48 (90.57\%) were followed-up until delivery; of these, 26 delivered before 37 weeks (54.17\%).

The comparison between time of delivery and MUCL showed a tendency of increased risk of PTL when MUCL was shorter than $25 \mathrm{~mm}$, however, without statistical significance (RR: $1.83,95 \%$ CI, 0.99-3.36, $p=0.09$ ). Nevertheless, a statistical difference was observed between the meantime in weeks from study admission to delivery $(2.98 \times 5.00, p=0.03)$ (-Table 2). 
Table 1 Characteristics of the analyzed sample

\begin{tabular}{|c|c|c|}
\hline \multicolumn{2}{|c|}{ Average age (years) } & $22.8(S D 7.32)$ \\
\hline \multicolumn{3}{|l|}{ Origin } \\
\hline \multicolumn{2}{|l|}{ Urban } & $60.38 \%$ \\
\hline \multicolumn{2}{|l|}{ Rural } & $39.62 \%$ \\
\hline \multicolumn{3}{|c|}{ Family income (\%) } \\
\hline \multicolumn{2}{|c|}{ Up to one minimum wage } & $62.26 \%$ \\
\hline \multicolumn{2}{|c|}{ More than one minimum wage } & $37.74 \%$ \\
\hline \multicolumn{3}{|l|}{ Education (\%) } \\
\hline \multicolumn{2}{|l|}{ Illiterate } & $3.77 \%$ \\
\hline \multicolumn{2}{|c|}{ Middle school level } & $52.83 \%$ \\
\hline \multicolumn{2}{|c|}{ High school level } & $39.62 \%$ \\
\hline \multicolumn{2}{|l|}{ College level } & $3.77 \%$ \\
\hline \multicolumn{3}{|c|}{ Previous pregnancies (\%) } \\
\hline \multicolumn{2}{|l|}{ Primiparous } & $56.60 \%$ \\
\hline \multicolumn{2}{|c|}{ Non-primiparous } & $43.40 \%$ \\
\hline \multicolumn{3}{|c|}{ Previous preterm delivery (\%) } \\
\hline \multicolumn{2}{|l|}{ Yes } & $21.74 \%$ \\
\hline \multicolumn{2}{|l|}{ No } & $78.26 \%$ \\
\hline \multicolumn{2}{|c|}{$\begin{array}{l}\text { Gestational age at study admission } \\
\text { (average weeks) }\end{array}$} & $\begin{array}{l}\text { Average: } 31.83 \\
\text { (SD 2.03) }\end{array}$ \\
\hline \multicolumn{2}{|c|}{$\begin{array}{l}\text { Patients who received tocolysis } \\
\text { (Nifedipine) }\end{array}$} & $88.68 \%$ \\
\hline \multicolumn{2}{|c|}{ MUCL by TVUTS } & $\begin{array}{l}\text { Average: } 21.7 \mathrm{~mm} \\
\text { (SD 8.9) }\end{array}$ \\
\hline & Cervix $<25 \mathrm{~mm}$ & $58.49 \%$ \\
\hline & Cervix $\geq 25 \mathrm{~mm}$ & $41.51 \%$ \\
\hline \multirow{2}{*}{$\begin{array}{l}\text { fFN rapid test } \\
\text { results }\end{array}$} & Positive & $41.51 \%$ \\
\hline & Negative & $58.49 \%$ \\
\hline
\end{tabular}

Abbreviations: fFN, fetal fibronectin; MUCL by TVUTS, measurement of uterine cervix length by transvaginal ultrasonography; SD, standard deviation.

The association of positive fFN rapid-test results with PTL was statistically significant (RR: 3.50; 95\% CI: 1.39-8.79; $p=0.002$ ); the same occurred in relation to the mean time in weeks from study admission to delivery $(1.94 \times 5.20$, $p=0.0003$ ) (-Table 2).

The risk for PTL was also increased when both results (fFN and MUCL) were used; however, this risk was lower than that considering the fFN rapid test alone (RR: 2.70 ; 95\% CI 1.08$6.72 ; p=0.002)$ as demonstrated by the average number of weeks from study admission to delivery (2.17) (-Table 2).

The MUCL results showed that the relative risk of PTL is $\mathrm{RR}=1.30,95 \% \mathrm{CI} 1.02-1.67$, and $p=0.11$ in the first 48 hours; $\mathrm{RR}=1.43,95 \% \mathrm{CI} \% 0.99-2.06$, and $p=0.12$ in up to 7 days; and $\mathrm{RR}=2.03,95 \% \mathrm{CI} 1.26-3.27$, and $p=0.008$ in up to 14 days (-Table 3 ).

When the fFN rapid test was positive, the relative risk for PTL in 48 hours was $R R=1.75,95 \% \mathrm{CI} 1.20-2.53$, and
Table 2 Relation between measurement of the uterine cervix, fetal fibronectin rapid test results, and the outcome of preterm delivery

\begin{tabular}{|c|c|c|c|}
\hline \multicolumn{4}{|c|}{ MUCL $<25$ mm X PTD } \\
\hline $\begin{array}{l}\text { Relative } \\
\text { risk }\end{array}$ & 1.83 & $95 \%$ Cl 0.99-3.36 & $p=0.09^{\mathrm{a}}$ \\
\hline \multicolumn{4}{|c|}{ Mean time between testing and delivery } \\
\hline & $\mathrm{MUCL}<25 \mathrm{~mm}$ & 2.98 weeks & $p=0,03^{b}$ \\
\hline & $\mathrm{MUCL} \geq 25 \mathrm{~mm}$ & \multicolumn{2}{|l|}{5.00 weeks } \\
\hline \multicolumn{4}{|c|}{ fFN rapid test $X$ PTD } \\
\hline $\begin{array}{l}\text { Relative } \\
\text { risk }\end{array}$ & 3.5 & $95 \%$ Cl 1.39-8.79 & $p=0.002^{\mathrm{a}}$ \\
\hline \multicolumn{4}{|c|}{ Mean time between testing and delivery } \\
\hline & Positive fFN & 1.94 weeks & $p=0.0003^{b}$ \\
\hline & Negative fFN & \multicolumn{2}{|l|}{5.20 weeks } \\
\hline \multicolumn{4}{|c|}{ Both tests X PTD } \\
\hline $\begin{array}{l}\text { Relative } \\
\text { risk }\end{array}$ & 2.70 & $95 \%$ Cl 1.08-6.72 & $p=0.002^{a}$ \\
\hline \multicolumn{3}{|c|}{ Mean time between testing and delivery } & 2.17 weeks \\
\hline
\end{tabular}

Abbreviations: $\mathrm{Cl}$, confidence interval; fFN, fetal fibronectin; $\mathrm{MUCL}$, measurement of uterine cervix length; PTD, preterm delivery. p:p-value. Statical tests: $\mathrm{a}-\mathrm{X}^{2}$; b-T test.

Table 3 Risk for preterm delivery outcome in 48 hours and 7 and 14 days relative to measurement of the uterine cervix and fetal fibronectin results

\begin{tabular}{|c|c|c|c|}
\hline \multicolumn{4}{|l|}{ Evolution to PTD } \\
\hline & $\begin{array}{l}\text { Within } \\
48 \text { hours }\end{array}$ & $\begin{array}{l}\text { In up to } \\
7 \text { days }\end{array}$ & $\begin{array}{l}\text { In up to } \\
14 \text { days }\end{array}$ \\
\hline \multirow[t]{4}{*}{$\mathrm{MUCL}<25 \mathrm{~mm}$} & $F=16.67 \%$ & $F=25.00 \%$ & $\mathrm{~F}=35.41 \%$ \\
\hline & $R R=1.30$ & $R R=1.43$ & $R R=2.03$ \\
\hline & $p=0.11$ & $p=0.12$ & $p=0.008$ \\
\hline & $\begin{array}{l}95 \% \mathrm{Cl} \\
1.02-1.67\end{array}$ & $\begin{array}{l}95 \% \mathrm{Cl} \% \\
0.99-2.06\end{array}$ & $\begin{array}{l}95 \% \mathrm{Cl} \\
1.26-3.27\end{array}$ \\
\hline \multirow[t]{4}{*}{ Positive fFN } & $\mathrm{F}=18.75 \%$ & $F=29.17 \%$ & $F=33.33 \%$ \\
\hline & $\mathrm{RR}=1.75$ & $\mathrm{RR}=2.88$ & $R R=3.57$ \\
\hline & $p=0.0006$ & $p=0.0001$ & $p=0.0002$ \\
\hline & $\begin{array}{l}95 \% \mathrm{Cl} \\
1.20-2.53\end{array}$ & $\begin{array}{l}95 \% \mathrm{Cl} \\
1.57-5.31\end{array}$ & $\begin{array}{l}95 \% \mathrm{Cl} \\
1.63-7.81\end{array}$ \\
\hline \multirow{4}{*}{$\begin{array}{l}\mathrm{MUCL}<25 \mathrm{~mm} \\
\& \\
\text { positive fFN }\end{array}$} & $F=16.67 \%$ & $F=22.91 \%$ & $F=27.08 \%$ \\
\hline & $\mathrm{RR}=1.74$ & $\mathrm{RR}=2.22$ & $R R=2.76$ \\
\hline & $p=0.0001$ & $p=0.0001$ & $p=0.0002$ \\
\hline & $\begin{array}{l}95 \% \mathrm{Cl} \\
1.14-2.64\end{array}$ & $\begin{array}{l}95 \% \mathrm{Cl} \\
1.22-4.04\end{array}$ & $\begin{array}{l}95 \% \mathrm{Cl} \\
1.27-5.96\end{array}$ \\
\hline
\end{tabular}

Abbreviations: $\mathrm{Cl}$, confidence interval; $\mathrm{F}$, frequency; fFN, fetal fibronectin; MUCL, measurement of uterine cervix length; $p$, $\mathrm{p}$ value; PTD, preterm delivery; RR, relative risk.

Statistical test: $X^{2}$.

$p=0.006 ; \mathrm{RR}=2.88,95 \% \mathrm{CI}, 1.57-5.31$, and $p=0.0001$ in up to 7 days; and $\mathrm{RR}=3.57,95 \% \mathrm{CI} 1.63-7.81$, and $p=0.0002$ in up to 14 days (-Table 3 ).

A significant association with PTL was observed in all scenarios when evaluating the positivity of both tests (MCCU 
$<25 \mathrm{~mm}$ and positive fFN); the relative risk for PTL was $\mathrm{RR}=1.74,95 \%$ CI 1.14-2.64; and $p=0.0001$ in 48 hours; $\mathrm{RR}=2.22,95 \% \mathrm{CI} 1.22-4.04, p=0.0001$ in up to 7 days; and $\mathrm{RR}=2.76,95 \% \mathrm{CI} 1.27-5.96$, and $p=0.0002$ in up to 14 days (-Table 3).

\section{Discussion}

Although digital uterine cervix evaluation is part of the routine examination of patients who are at high risk for prematurity, this method is not often a safe way to recognize early cervical alterations. Yamasaki et $\mathrm{al}^{13}$ verified that the MUCL by TVUS showed a better accuracy for PTL diagnosis than vaginal touch in pregnant women at high risk because the portion above the anterior fornix can be evaluated through TVUS but not through vaginal touch.

In this study, considering only the cervices $<25 \mathrm{~mm}$, there is no statistically significant increase of risk of PTD, but the interval of time between the measurement and the delivery was statistically different, two weeks longer in pregnant women when the MUCL $>25 \mathrm{~mm}$. In 1996, Iams et al ${ }^{14}$ reported that MUCL under $25 \mathrm{~mm}$ indicated a PTD positive predictive value of $17.8 \%$ and negative of $97 \%$. Therefore, the MUCL helps distinguishing pregnant women from false PTL, which may prevent unnecessary interventions. Likewise, a pregnant woman with short MUCL deserves extended attention through the performance of additional tests using antenatal corticoid and preventive measures.

Tanvir et al (2014), ${ }^{15}$ evaluated the MUCL in 130 pregnant women between 22 and 24 weeks of GA using the length $<25 \mathrm{~mm}$ as the cut-off point. That study reports that among the patients with short MUCL (16 women), 13 evolved to PTD, thus demonstrating the importance of this measurement as a PTD predicting factor. ${ }^{15}$ To et al $(2001)^{16}$ demonstrated the inverse relationship between PTD risk and MUCL; the risk can reach $78 \%$ when the length is shorter than $5 \mathrm{~mm}$, decreases to $4 \%$ when the length is up to $15 \mathrm{~mm}$, and decreases to $0.5 \%$ when the length is greater than $50 \mathrm{~mm}$ in asymptomatic patients. Our study highlighted a similar trend; the difference in the magnitude of the reduction may be due to the small sample, did not allow our results to reach statistical significance.

Fetal fibronectin is an extracellular matrix glycoprotein that is produced by amniocytes and cytotrophoblasts and has been shown to predict spontaneous preterm birth. ${ }^{17}$ Our study observed the use of the qualitative fFN test showed an increase of PTD isolated or in association with MUCL, and when the test was negative, the time between to delivery was greater than three weeks, showing superior to MUCL. Similar results in a multicenter study, Brujin et al (2016), ${ }^{18}$ demonstrated the comparison between the quantitative and qualitative results of fFN tests associated with MUCL and the risk for PTD in seven days. These authors showed that the quantitative fFN test presents the same accuracy compared with the qualitative fFN test associated with MUCL. However, the association between MUCL and the qualitative measure of fFN shows an advantageous capacity to predict PTD. ${ }^{18}$ Other studies demonstrated that the use of the qualitative fFN test alone was not enough to increase the prediction of PTD compared with the use of the fFN test in association with MUCL. ${ }^{19,20}$ Deshpande et al (2013), ${ }^{21}$ evaluated the cost-effectiveness of using the rapid fibronectin test in symptomatic pregnant women and reported that the test, used in isolation, had moderate accuracy and could identify patients with negative test results who would not need intervention. Magro-Malosso et al (2017), ${ }^{22}$ observed that positive fFN tests were detected in 33\% of symptomatic patients and significantly associated with PTD at 34 weeks and within 48 hours, 7, 14, and 21 days after admission $(p<0.05)$; this association was not observed in the asymptomatic group. This study showed an increased risk of PTD, mainly when analyzed the use of fFN test and both tests. The MUCL increased the risk of PTD only within 14 weeks. Van Baaren et al (2013) $)^{23}$ concluded that the best cost-benefit ratio is in the combined application of the fFN test and MUCL. HadžiLegal et al $(2016)^{24}$ reported similar results in symptomatic pregnant women observing that the combination of these tests turned out to be an excellent predictor of PTD within 14 days of admission. ${ }^{24}$ Despite the similarities to our results, these authors state that there are no high-quality studies about the evaluation of this test, reducing the magnitude of our results.

In another study with a small sample of 30 patients, the fFN test used in this sample was not shown to be predictive enough to inform the decisions of clinicians and pregnant mothers to delay evacuation to a regional birthing center. ${ }^{25}$ Similar results in systematic review and meta-analysis of randomized clinical trials the fFN testing in singleton gestations with threatened preterm labor is not associated with the prevention of preterm birth or improvement in perinatal outcome but is associated with higher costs. ${ }^{17}$ The different trends shown by our results may be due to the small sample and a distinct population group of Brazilian women not included in these studies.

Our study has several strengths, the main one being that it is the first study in the Northeast of Brazil that associates fFN e MUCL in PTD, and some weaknesses, including the facts that this study is analytical and non-interventional and has a small sample.

\section{Conclusion}

In symptomatic pregnant women, we conclude that the MUCL $<25 \mathrm{~mm}$ and positive fFN rapid test indicate increased risk for PTD. Further studies with larger sample sizes could contribute in supporting the results presented in the current study.

\section{Conflict of Interest}

The authors have no conflicts of interest to declare.

\section{Collaborations}

Pinheiro Filho T. R. C., Pessoa V. R., Lima T. S., Castro M. M. and Linhares J. J. contributed to the project conception, interpretation of data; critical revision of relevant intellectual content and final approval of the version to be published. 


\section{Acknowledgments}

We thank Santa Casa de Misericórdia de Sobral, which provided the study environment and patients who were willing to participate in the study. We also thank the Department of Education and Research (Departamento de Ensino e Pesquisa [DEPE, in the Portuguese acronym]) of Santa Casa de Misericórdia de Sobral.

\section{References}

1 Figo Working Group On Best Practice In Maternal-Fetal Medicine; International Federation of Gynecology and Obstetrics. Best practice in maternal-fetal medicine. Int J Gynaecol Obstet 2015;128 (01):80-82. Doi: 10.1016/j.ijgo.2014.10.011

2 Iams JD, Romero R, Culhane JF, Goldenberg RL. Primary, secondary, and tertiary interventions to reduce the morbidity and mortality of preterm birth. Lancet 2008;371(9607):164-175. Doi: 10.1016/ S0140-6736(08)60108-7

3 Goldenberg RL, Culhane JF, Iams JD, Romero R. Epidemiology and causes of preterm birth. Lancet 2008;371(9606):75-84. Doi: 10.1016/S0140-6736(08)60074-4

4 Souza RT, Cecatti JG, Passini R Jr, et al; Brazilian Multicenter Study on Preterm Birth study group. The burden of provider-initiated preterm birth and associated factors: evidence from the Brazilian Multicenter Study on Preterm Birth (EMIP). PLoS One 2016;11 (02):e0148244. Doi: 10.1371/journal.pone.0148244

5 Gao L, Zhang JP, Chen H, et al. Fetal fibronectin detection for preterm birth prediction. Genet Mol Res 2014;13(01):1323-1328. Doi: 10.4238/2014.February.28.4

6 Bittar RE, Zugaib M. [Risk predictors for preterm birth]. Rev Bras Ginecol Obstet 2009;31(04):203-209. Doi: 10.1590/S0100-72032 009000400008

7 Rades E, Bittar RE, Zugaib M. Direct determinants of elective preterm birth and neonatal results. Rev Bras Ginecol Obstet 2004; 26:655-662. Doi: 10.1590/S0100-72032004000800010

8 Oliveira TA, Carvalho CM, Souza E, et al. Evaluation of risk for preterm delivery by fetal fibronectin test and measurement of uterine cervix. Rev Bras Ginecol Obstet 2000;22:633-639. Doi: 10.1590/S0100-72032000001000006

9 Bezerra LC, Oliveira SM, Latorre MR. Prevalência e fatores associados à prematuridade entre gestantes submetidas à inibição de trabalho de parto prematuro. Rev Bras Saude Mater Infant 2006; 6:223-229. Doi: 10.1590/S1519-38292006000200010

10 Zalar RW Jr. Early cervical length, preterm prelabor and gestational age at delivery. Is there a relationship? J Reprod Med 1998; 43(12):1027-1033

11 Carvalho MH, Bittar RE, Gonzales M, Brizot ML, Zugaib M. Risk assessment for spontaneous preterm delivery according to cervical length in the first and second trimesters of pregnancy. Rev Bras Ginecol Obstet 2002;24:463-468. Doi: 10.1590/S0100-7203200200 0700006

12 Dória MT, Spautz CC. Trabalho de parto prematuro predição e prevenção. Femina 2011;9:443-449

13 Yamasaki AA, Bittar RE, Fonseca ES, Martinelli S, Sasaki S, Zugaib M. Prevention of preterm birth: use of digital examination and transvaginal ultrasonography. Rev Bras Ginecol Obstet 1998; 20:350-356. Doi: 10.1590/S0100-72031998000600008

14 Iams JD, Goldenberg RL, Meis PJ, et al; National Institute of Child Health and Human Development Maternal Fetal Medicine Unit Network. The length of the cervix and the risk of spontaneous premature delivery. N Engl J Med 1996;334(09):567-572. Doi: 10.1056/NEJM199602293340904

15 Tanvir GS, Ghose S, Samal S, Armugam S, Parida P. Measurement of cervical biometry using transvaginal ultrasonography in predicting preterm labor. J Nat Sci Biol Med 2014;5(02):369-372. Doi: 10.4103/0976-9668.136189

16 To MS, Skentou C, Liao AW, Cacho A, Nicolaides KH. Cervical length and funneling at 23 weeks of gestation in the prediction of spontaneous early preterm delivery. Ultrasound Obstet Gynecol 2001;18(03):200-203. Doi: 10.1046/j.1469-0705.2001.00437.x

17 Berghella V, Saccone G. Fetal fibronectin testing for prevention of preterm birth in singleton pregnancies with threatened preterm labor: a systematic review and metaanalysis of randomized controlled trials. Am J Obstet Gynecol 2016;215(04):431-438. Doi: 10.1016/j.ajog.2016.04.038

18 Bruijn MM, Kamphuis EI, Hoesli IM, et al. The predictive value of quantitative fibronectin testing in combination with cervical length measurement in symptomatic women. Am J Obstet Gynecol 2016; 215(06):793.e1-793.e8. Doi: 10.1016/j.ajog.2016.08.012

19 Bruijn M, Vis JY, Wilms FF, et al. Quantitative fetal fibronectin testing in combination with cervical length measurement in the prediction of spontaneous preterm delivery in symptomatic women. BJOG 2016;123(12):1965-1971. Doi: 10.1111/1471-0528.13752

20 Gomez R, Romero R, Medina L, et al. Cervicovaginal fibronectin improves the prediction of preterm delivery based on sonographic cervical length in patients with preterm uterine contractions and intact membranes. Am J Obstet Gynecol 2005;192(02): 350-359. Doi: 10.1016/j.ajog.2004.09.034

21 Deshpande SN, van Asselt AD, Tomini F, et al. Rapid fetal fibronectin testing to predict preterm birth in women with symptoms of premature labour: a systematic review and cost analysis. Health Technol Assess 2013;17(40):1-138. Doi: 10.3310/hta17400

22 Magro-Malosso E, Seravalli V, Cozzolino M, Spitaleri M, Susini T, Di Tommaso M. Prediction of preterm delivery by fetal fibronectin in symptomatic and asymptomatic women with cervical length $\leq 20 \mathrm{~mm}$. J Matern Fetal Neonatal Med 2017;30(03):294-297. Doi: 10.3109/14767058.2016.1171309

23 van Baaren GJ, Vis JY, Grobman WA, Bossuyt PM, Opmeer BC, Mol BW. Cost-effectiveness analysis of cervical length measurement and fibronectin testing in women with threatened preterm labor. Am J Obstet Gynecol 2013;209(05):436.e1-436.e8. Doi: 10.1016/ j.ajog.2013.06.029

24 Hadži-Legal M, Markova AD, Stefanovic M, Tanturovski M. Combination of selected biochemical markers and cervical length in the prediction of impending preterm delivery in symptomatic patients. Clin Exp Obstet Gynecol 2016;43(01):154-160. Doi: 10.12891/ceog2046.2016

25 Healey GK, Macdonald WA, Grzybowski S, Nevin R, Kornelsen J, Hogg WE. Exploring fetal fibronectin testing as a predictor of labour onset: In parturient women from isolated communities. Can Fam Physician 2018;64(03):e108-e114[REMOVED HYPERLINK FIELD] 